\title{
Assessment of uranium in soils of Kota Samarahan, Sarawak
}

Cite as: AIP Conference Proceedings 2295, 020012 (2020); https://doi.org/10.1063/5.0031499

Published Online: 03 December 2020

\section{Boon Siong Wee, Andelin Fastina Del, and Kuan Ying Kok}
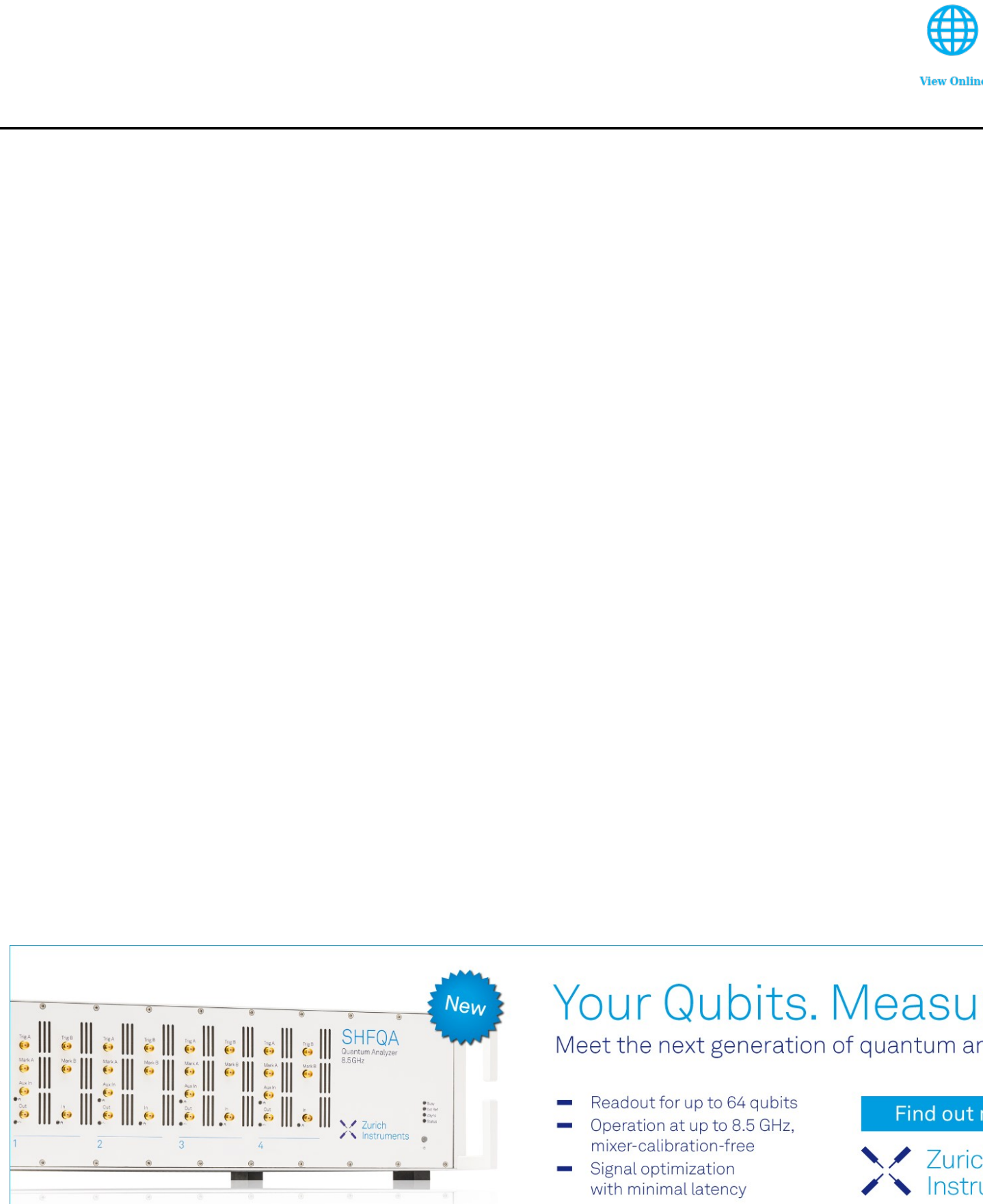

\section{Your Qubits. Measured.}

Meet the next generation of quantum analyzers

- Readout for up to 64 qubits

- Operation at up to $8.5 \mathrm{GHz}$,

- Signal optimization with minimal latency 


\title{
Assessment of Uranium in Soils of Kota Samarahan, Sarawak
}

\author{
Boon Siong Wee ${ }^{1, a)}$, Andelin Fastina Del ${ }^{1, b)}$ and Kuan Ying Kok ${ }^{2, c)}$ \\ ${ }^{1}$ Resource Chemistry Program, Faculty of Resource Science \& Technology, Universiti Malaysia Sarawak, 94300 \\ Kota Samarahan, Sarawak, Malaysia. \\ ${ }^{2}$ Malaysian Nuclear Agency, Bangi, 43000 Kajang, Selangor, Malaysia. \\ a)Corresponding author: swboon@unimas.my \\ b)hellyeahann@gmail.com \\ c)kyk1000@nuclearmalaysia.gov.my
}

\begin{abstract}
A study on the levels of uranium (U) in urban soils of Samarahan was conducted to assess the contamination of uranium in the soil. Uranium was extracted from soil samples using aqua regia and extract was analyzed using ICP-OES. Results showed that acidic soils influence the absorption of uranium in soils and the binding of uranium due to the presence of organic matter. The highest concentration of uranium obtained from UM2 with $60 \mathrm{mg} \mathrm{kg}^{-1}$ and the lowest from UM3 with $<0.01 \mathrm{mg} \mathrm{kg}^{-1}$. Based on the contamination factors (CF) and geo-accumulation index (Igeo) calculations, the locations presented from low to high contamination of uranium and fall in Class 0 to Class 3 . Most of the concentrations of the studied areas are within the tolerable value which was $23 \mathrm{mg} \mathrm{kg}^{-1}$ for residential lands and $33 \mathrm{mg} \mathrm{kg}^{-1}$ for commercial lands except for UM2 based on the soil quality guidelines. In conclusion, the current U concentrations in soil of Kota Samarahan do not pose any hazardous effect towards the environment and human health.
\end{abstract}

\section{INTRODUCTION}

Soil is an example of basic natural resources besides water and air. According to Andrews et al. (2002), soil, water and air qualities are the three components of environmental quality. Contrary, the quality of the soil is, however, not determine based on the level of soil pollution rather than defined broadly as "the functionality of the soil in the ecosystem, which needed to maintain the biological productivity, environmental quality and enhancing the health of plants and animals (Doran and Parkin, 1994, 1996). Recently, the study regarding the level of concentration of natural radionuclides and their distributions in the environment has spiked an interest to several fields in science (El-Aydarous, 2007).

One of the main interests was the studies regarding the presence of $U$ in soils. Saat et al. (2010) stated that $U$ can be found widely in nature with the concentrations of $2-4 \mathrm{mg} \mathrm{kg}^{-1}$ occurring in most rocks and the earth's crust. The most commonly found $\mathrm{U}$ isotope is the ${ }^{238} \mathrm{U}$ isotope that undergoes 13 different radionuclides to produce ${ }^{206} \mathrm{~Pb}$ by emitting alpha $(\alpha)$ or beta $(\beta)$ radiation and even gamma $(\gamma)$ radiation, although at various energies (Todorov \& Illieva, 2006; Sánchez-González et al, 2014). Several studies performed worldwide have measured and reported the levels of U in soils (Saat et al., 2010; Cinelli et al., 2017; Santos-Francés et al., 2017).

Uranium that being released to the environment is able to cause plausible hazard of chemical and radiological toxicity to human health due to the emission of the ionizing radiation including the heavy metal toxicity (SantosFrancés et al., 2017). According to Elles and Lee (2002), the concentration of natural radionuclides that existed in rocks and soils is not a concern towards human health including environment. There are risks towards the human 